\title{
KERAGAMAN LAMUN DI TELUK BANTEN, PROVINSI BANTEN
}

\section{(SEAGRASS DIVERSITY IN BANTEN BAY, THE PROVINCE OF BANTEN)}

\author{
Citra Satrya ${ }^{1,2}$, Muhammad Yusuf ${ }^{2}$, Muhandis Shidqi $^{3}$, Beginer Subhan ${ }^{4}$, Dondy Arafat ${ }^{4}$, \\ Fitryah Anggraeni ${ }^{4}$ \\ ${ }^{1}$ Corresponding author \\ ${ }^{2}$ Ilmu Kelautan, Fakultas Perikanan dan Ilmu Kelautan, Universitas Brawijaya, \\ Jl. Veteran No 1. Malang. 65145. Indonesia \\ E-mail: satryacitra@ub.ac.id \\ ${ }^{3}$ Subdit Identifikasi Pulau, KP3K, Kementerian Kelautan Perikanan. \\ ${ }^{4}$ Departemen Ilmu dan Teknologi Kelautan, Fakultas Perikanan dan Ilmu Kelautan, IPB
}

\begin{abstract}
Seagrass ecosystem is one distinguish component, which has an important role in tropical ecology. Seagrass also known as a potential organisms that contain bioactive compounds as raw material for medicine, so its distribution is important to be analyzed. The aim of this study were to provided information about distribution, diversity, density, and percent cover of seagrass in Banten Bay. This study was conducted by Line Intercept Transect (LIT) method at three station. There are five species of seagrass that were found in Banten Bay, namely: Cymodocea rotundata, Cymodocea serrulata, Enhalus acoroides, Halophila ovalis, dan Thalassia hemprichii. The highest density of seagras found at Tunda Island (193 individu/ $\left.m^{2}\right)$, and the lowest found at Panjang Island (44 individu/ $\left.\mathrm{m}^{2}\right)$. The highest percent cover of seagrass found at Kalih Island $(90 \%)$, while the lowest found at Panjang Island (62.5\%). Enhalus acoroides is the most dominant species of seagrass that found on Banten Bay. The percent cover of seagrass inform that seagrass ecosystem in Banten Bay relatively healthy/ wealthy.
\end{abstract}

Keywords: Seagrass, Diversity, Banten Bay

\section{ABSTRAK}

Ekosistem lamun merupakan salah satu penyusun pantai tropis yang memiliki peranan penting dalam struktur ekologi wilayah pesisir, selain itu lamun juga diketahui memiliki potensi dimanfaatkan sebagai bahan baku farmasi, sehingga keberadaan lamun di suatu wilayah sangat penting untuk diketahui dan dianalisis. Penelitian ini dilakukan dengan metode transek garis pada tiga stasiun, dan bertujuan untuk memberikan informasi keragaman, kerapatan, dan penutupan jenis lamun di Teluk Banten. Padang lamun di Teluk Banten terdiri dari lima jenis, yaitu: Cymodocea rotundata, Cymodocea serrulata, Enhalus acoroides, Halophila ovalis, dan Thalassia hemprichii. Kerapatan lamun tertinggi ditemukan di Pulau Tunda (193 individu/ $\mathrm{m}^{2}$ ), dan terendah di Pulau Panjang (44 individu $\left./ \mathrm{m}^{2}\right)$. Penutupan lamun terendah ditemukan pada Pulau Panjang (62.5\%), sedangkan tertinggi pada Pulau Kalih (90\%), dan didominasi oleh jenis Enhalus acoroides. Nilai penutupan lamun ini menunjukan ekosistem lamun di Teluk Banten tergolong sehat/kaya.

Kata kunci: Lamun, Keragaman, Teluk Banten

\section{PENDAHULUAN}

Laut tropis memiliki tiga ekosistem pesisir yang tidak terpisahkan baik fungsi ataupun fisik, yaitu Ekosistem Lamun, Ekosistem Mangrove, serta Ekosistem Terumbu Karang. Ekosistem lamun merupakan salah satu penyusun pantai yang memiliki peranan penting dalam struktur ekologi wilayah pesisir, antara lain sebagai (1) produsen primer di laut dangkal; (2) habitat hidup biota; (3) perangkap sedimen; dan (4) pendaur zat hara (Azkab, 1999). Lamun juga diketahui memiliki potensi dimanfaatkan sebagai bahan baku farmasi. Raja-Kannan et al. (2010) memaparkan Thalassia hemprichii memiliki potensi bioaktif sebagai antioksidan dan mengandung senyawa golongan fenolik. Thalassia hemprichii yang dikoleksi dari Pamban, Tamil Madu, India diketahui mengandung senyawa bioaktif potensial sebagai antibakteri, antifungi, antiprotozoa, antiviral, antifertility, dan yang bahan obat-obatan yang berpengaruh pada sistem cardiovascular (Laksmi et al., 2006).

Sehubungan dengan peran ekologis dan potensi pemanfaatan lamun yang luas, maka keberadaan lamun di suatu wilayah sangat penting untuk diketahui dan dianalisis. Penelitian ini 
bertujuan untuk memberikan informasi keragaman, kerapatan, dan penutupan jenis lamun di Teluk Banten. Informasi tersebut diharapkan dapat digunakan sebagai variabel dasar dalam menentukan kebijakan untuk pemanfaatan dan pengelolaan wilayah di Teluk Banten.

\section{METODOLOGI PENELITIAN}

Penelitian dilakukan di Teluk Banten, Provinsi Banten pada bulan November 2012, di tiga lokasi, yaitu Pulau Panjang, Pulau Tunda dan Pulau Kalih (Gambar 1). Pengamatan dan pengambilan contoh dilakukan dengan menggunakan metode transek garis. Pengamatan lamun dilakukan pada saat air laut mengalami surut dengan kedalaman 20--100 meter. Sebelum melaksanakan pengamatan transek, lebih dahulu dilakukan pengamatan pengenalan lapangan pada daerah yang akan diteliti untuk menentukan titik- titik transek (English et al., 1994). Lokasi pengamatan dicatat posisi geografisnya dengan meng-gunakan Global Positioning System. Pengamatan lapangan dikerjakan dengan berjalan kaki ketika air sedang surut maupun dengan snorkeling ketika air sedang pasang atau tempat-tempat yang mempunyai kedalaman air lebih dari 1 meter.

Transek ditarik tegak lurus dari pinggir pantai sampai ke daerah yang tidak ditemukan lamun. Pada transek tersebut ditarik rol meter sepanjang 50-100 meter. Jarak transek satu dengan yang lain 100 meter dengan jarak antar titik pengambilan sampel sepanjang 25 meter. Lamun yang dilalui meteran tersebut dicatat jenisnya, komposisinya (tunggal atau campuran), jarak sebaran lamun, luas tutupan, jenis substrat, dan kedalaman air pada saat melakukan pengamatan. Pada setiap titik diambil contoh dengan menggunakan bingkai (frame) $25 \times 25 \mathrm{~cm}$.

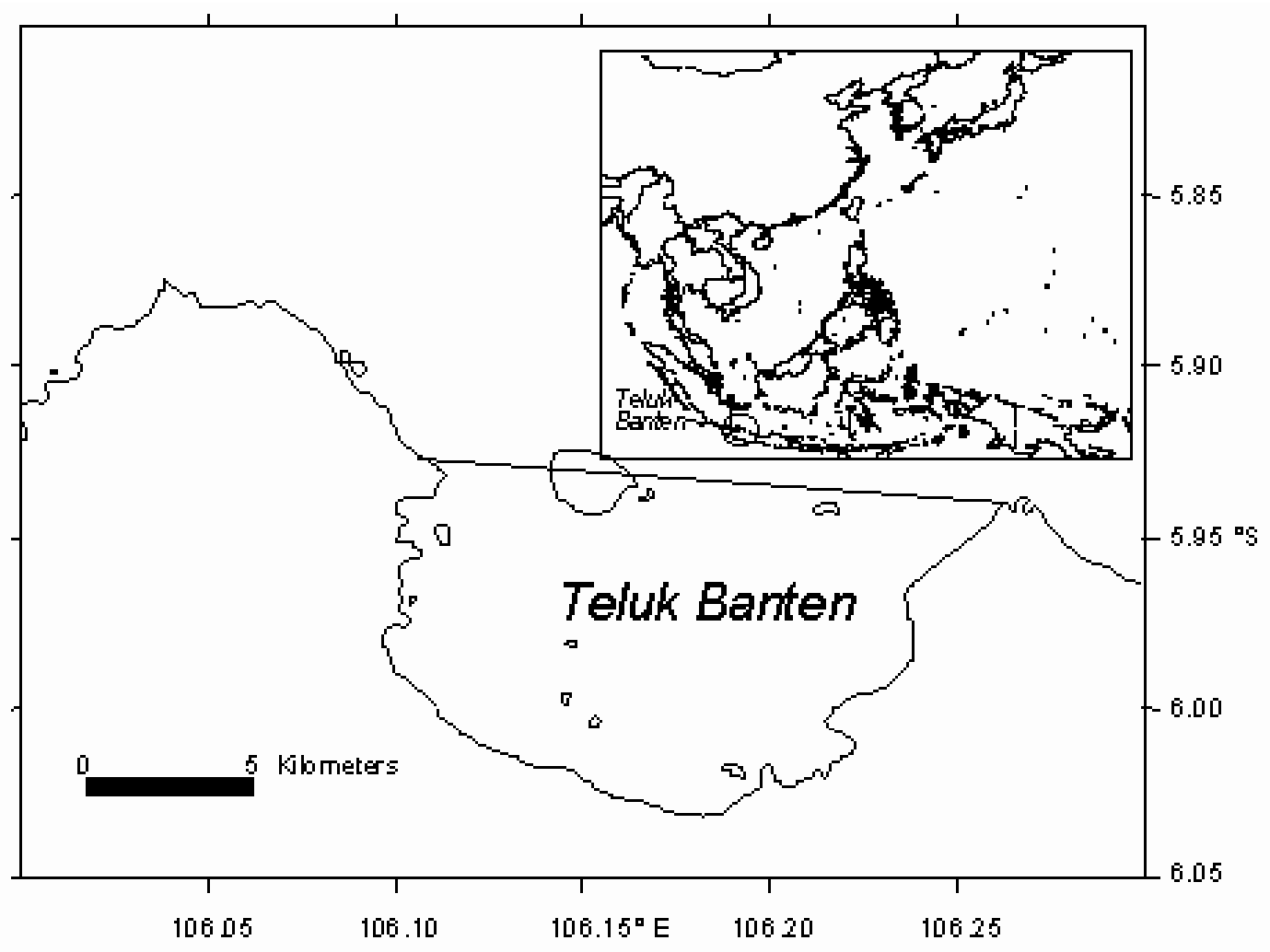

Sumber: Lindeboom et al. (2000)

Gambar 1. Lokasi penelitian di Teluk Banten, Provinsi Banten 


\section{HASIL DAN PEMBAHASAN}

\subsection{Keragaman Lamun}

Keragaman jenis lamun tertinggi selama penelitian ditemukan di Pulau Tunda (Tabel 1), dimana terdapat lima jenis lamun yang hidup bersama membentuk padang lamun. Padang lamun yang ditemukan di Pulau Kalih terdiri dari dua jenis lamun, yaitu: Enhalus acoroides dan Halophila ovalis, sedangkan penyusun padang lamun di Pulau Panjang adalah jenis: Cymodocea serrulata dan Enhalus accoroides. Enhalus acoroides merupakan jenis lamun yang ditemukan meluas di semua lokasi pengambilan data lamun di Teluk Banten (Tabel 1).

Enhalus acoroides memiliki ciri yang sangat khas dan mudah dikenali secara visual, dengan ukuran panjang daun mencapai $30 \mathrm{~cm}$, lebar daun lebih dari $1 \mathrm{~cm}$, serta rizhoma yang tebal dan memiliki tanda garis hitam melingkar (Waycott, 2004). Enhalus acoroides umum ditemukan hidup pada habitat perairan semi tertutup, tenang, dengan substrat yang padat, seperti di daerah teluk dan lagoon (Den Hartog, 1970). Lamun jenis ini memiliki distribusi yang luas, dilaporkan oleh Pratiwi (2010) ditemukan di perairan Teluk Lampung, Teluk Gilimanuk (Al-Hakim \& Wahyuni 2009), Kepulauan Seribu (Mardesyawati \& Anggraeni, 2009), dan Pantai Molas, Manado (Maabuat et al., 2012).

Terdapat lima jenis lamun yang dapat tumbuh dan berkembang biak dengan baik di perairan Teluk Banten, yaitu Cymodocea rotundata, Cymodoceaa serrulata, Enhalus acoroides, Halophila ovalis, dan Thalassia hemprichii. Kelima jenis lamun tersebut tergolong dalam empat genus berbeda, serta dua famili yang berbeda pula. Genus Enhalus, Thalassia, dan Halophila termasuk dalam Famili Hydrocharitaceae, dan genus Cymodocea masuk dalam Famili Cymodocaceae.

Hasil penelitian menunjukkan 5 dari 12 (42\%) jenis lamun di Indonesia dapat ditemukan di Teluk Banten (Tabel 2). Dari perbandingan jenis lamun yang ada di Indonesia, Teluk Gilimanuk, Teluk Lampung, dan Teluk Banten, terlihat bahwa kelima jenis lamun yang ditemukan saat penelitian memiliki penyebaran yang luas. Keragaman jenis lamun yang ditemukan di Teluk Banten lebih rendah dari keragaman jenis lamun yang ditemukan di Teluk Gilimanuk (Al-Hakim \& Wahyuni, 2009) dan Teluk Lampung (Pratiwi, 2010).

\subsection{Kerapatan Lamun}

Kerapatan lamun akan menggambarkan berapa jumlah individu lamun yang ditemukan dalam satu satuan luas di sebuah lokasi pengamatan. Kerapatan total lamun di Teluk Banten bervariasi antara 44 hingga 193 individu $/ \mathrm{m}^{2}$. Kerapatan total lamun tertinggi ditemukan di Pulau Tunda, dan terendah di Pulau Panjang (Tabel 3). Kerapatan total lamun di Pulau Kalih, adalah 166 individu/ $\mathrm{m}^{2}$, terdiri dari 46 individu Enhalus acoroides dan 120 individu Halophila ovalis, pada setiap meter perseginya.

Tingginya kerapatan total lamun di Pulau Tunda diduga karena Pulau Tunda memiliki dua tipe substrat dengan karakteristik yang berbeda, yaitu pasir dengan pecahan karang dan pasir berlumpur. Perbedaan karakter fisik substrat tersebut memberikan peluang yang lebih besar pada beberapa jenis lamun untuk hidup didalamnya. Lokasi padang lamun di Pulau Tunda yang berdekatan dengan ekosistem mangrove juga menjadi alasan besarnya nilai kerapatan lamun di lokasi tersebut, dimana pasokan nutrien yang tinggi dari ekosistem mangrove dapat dimanfaatkan oleh lamun, sehingga pertumbuhan dan perkembangbiakan lamun meningkat.

\subsection{Penutupan Lamun}

Penutupan total lamun di perairan Teluk Banten sangat variatif, berkisar antara 62.5\% hingga 90\%. Penutupan total lamun terendah ditemukan di Pulau Panjang dan didominasi oleh jenis Enhalus acoroides, sedangkan penutupan total lamun tertinggi ditemukan di Pulau Kalih dan didominasi lamun jenis Enhalus acoroides. Penutupan total lamun di Pulau Tunda cukup tinggi, yaitu 86.5\% didominasi oleh jenis Cymodocea serrulata.

Enhalus acoroides mendominasi hampir di seluruh pulau, ini karena lamun ini memiliki morfologi khas, dengan ukuran yang relatif besar jika dibandingkan dengan lamun jenis yang lain. Panjang daun lamun Enhalus acoroides yang tercatat selama penelitian 
mencapai $54 \mathrm{~cm}$, sedangkan daun lamun jenis lain, seperti Cymodocea rotundata, Cymodocea serrulata, Thalassia hemprichii rata-rata hanya mencapai $20 \mathrm{~cm}$, bahkan lamun jenis Halophila ovalis hanya memiliki tinggi sekitar $5 \mathrm{~cm}$. Hal ini menunjukkan bahwa daun Enhalus acoroides dapat menaungi substrat lebih luas dari pada empat jenis lamun lain yang ditemukan di Teluk Banten.
Berdasarkan Keputusan Menteri Negara Lingkungan Hidup No. 200 Tahun 2004 mengenai kriteria kerusakan dan pedoman penentuan status padang lamun, dimana tutupan lamun $\geq 60 \%$ tergolong kaya; $30-59.9 \%$ tergolong kurang; dan $\leq 29.9 \%$ tergolong miskin. Hal ini menunjukan bahwa status padang lamun di Teluk Banten tergolong kaya, karena penutupan total lamun di setiap stasiun lebih dari $60 \%$.

Tabel 1. Keragaman jenis lamun di Teluk Banten, Provinsi Banten

\begin{tabular}{l|c|c|c}
\hline \multicolumn{1}{c|}{ Jenis } & Pulau Kalih & Pulau Tunda & Pulau Panjang \\
\hline Cymodocea rotundata & - & $*$ & - \\
Cymodocea serrulata & - & $*$ & $*$ \\
Enhalus accoroides & $*$ & $*$ & - \\
Halopila ovalis & $*$ & $*$ & - \\
Thalassia hemprichii & - & $*$ & $*$ \\
\hline
\end{tabular}

*) Ditemukan

-) Tidak ditemukan

Tabel 2. Keragaman jenis lamun di Indonesia, Teluk Gilimanuk, Teluk Lampung, dan Teluk Banten

\begin{tabular}{|c|c|c|c|c|c|}
\hline No. & Jenis & Indonesia $^{1}$ & Teluk Gilimanuk ${ }^{2}$ & Teluk Lampung 3 & Teluk Banten ${ }^{4}$ \\
\hline & Famili Hydrocharitaceae & & & & \\
\hline 1. & Enhalus acoroides & * & * & * & * \\
\hline 2. & Halophila decipiens & * & - & - & - \\
\hline 3. & Halophila minor & * & - & - & - \\
\hline 4. & Halophila ovalis & * & * & * & * \\
\hline 5. & Halophila spinulosa & * & - & - & - \\
\hline 6. & Thalassia hemprichii & * & * & * & * \\
\hline & Family Cymodocaceae & & & & \\
\hline 7. & Cymodocea rotundata & * & * & * & * \\
\hline 8. & Cymodocea serrulata & * & - & - & * \\
\hline 9. & Halodule pinifolia & * & * & * & - \\
\hline 10. & Halodule uninervis & * & * & * & - \\
\hline 11. & Syringodium isoetifoilum & * & - & - & - \\
\hline 12. & Thalassodendron cilliatum & * & - & - & - \\
\hline
\end{tabular}


Tabel 3. Kerapatan jenis lamun di Teluk Banten, Provinsi Banten

\begin{tabular}{l|l|l|l}
\hline \multirow{2}{*}{ Jenis } & \multicolumn{1}{|c|}{ Pulau Kalih } & \multicolumn{1}{|c|}{ Pulau Tunda } & \multicolumn{1}{c}{ Pulau Panjang } \\
\cline { 2 - 4 } & \multicolumn{1}{|c}{$\left(\mathrm{Ind} / \mathrm{m}^{2}\right)$} & \multicolumn{1}{|c}{$\left(\mathrm{Ind} / \mathrm{m}^{2}\right)$} & \multicolumn{1}{c}{$\left(\mathrm{Ind} / \mathrm{m}^{2}\right)$} \\
\hline Cymodocea rotundata & - & 57 & - \\
Cymodocea serrulata & - & 55 & 12 \\
Enhalus accoroides & 46 & 23 & 32 \\
Halopila ovalis & 120 & 7 & - \\
Thalassia hemprichii & - & 51 & - \\
Kerapatan Total Lamun & 166 & 193 & 44 \\
\hline
\end{tabular}

Tabel 4. Penutupan jenis lamun di Teluk Banten, Provinsi Banten

\begin{tabular}{l|l|l|l}
\hline \multirow{2}{*}{ Jenis } & \multicolumn{1}{|c|}{ Pulau Kalih } & \multicolumn{1}{|c|}{ Pulau Tunda } & \multicolumn{1}{c}{ Pulau Panjang } \\
\cline { 2 - 5 }$(\%)$ & \multicolumn{1}{|c}{$(\%)$} & \multicolumn{1}{c}{$(\%)$} \\
\hline Cymodocea rotundata & - & 7 & - \\
Cymodocea serrulata & - & 27.5 & 10 \\
Enhalus accoroides & 48 & 24 & 52.5 \\
Halopila ovalis & 42 & 3 & - \\
Thalassia hemprichii & - & 25 & - \\
Penutupan Total Lamun & 90 & 86.5 & 62.5 \\
\hline
\end{tabular}

\section{KESIMPULAN}

Kesimpulan dari kajian keragaman lamun yang dilakukan di Teluk Banten, Provinsi Banten, adalah: (1) Terdapat 5 dari 12 jenis lamun di Indonesia yang dapat dijumpai di Teluk Banten, yaitu: Cymodocea rotundata, Cymodocea serrulata, Enhalus acoroides, Halophila ovalis, dan Thalassia hemprichii; (2) Kerapatan lamun tertinggi di Teluk Banten ditemukan di Pulau Tunda (193 individu $\left./ \mathrm{m}^{2}\right)$, dan terendah di Pulau Panjang (44 individu $/ \mathrm{m}^{2}$ ), dengan penutupan lamun terendah ditemukan pada Pulau Panjang $(62.5 \%)$, dan tertinggi pada Pulau Kalih (90\%), yang didominasi oleh jenis Enhalus acoroides; (3) Nilai penutupan lamun tersebut menunjukan ekosistem lamun di Teluk Banten tergolong sehat/kaya.

\section{Ucapan Terima Kasih}

Penelitian ini dilakukan dalam serangkaian kegiatan yang diadakan oleh Subdit. Identifikasi Pulau, KP3K, Kementerian Kelautan Perikanan di Teluk Banten, Provinsi Banten.

\section{DAFTAR PUSTAKA}

Azkab, M.H. 1999. Pedoman inventtarisasi lamun. Oseana, Vol 24(1); $1-16$.

Al-Hakim, I.I. dan P.S. Wahyuni. 2009. Populasi suku Syllidae (Polychaeta) di padang lamun perairan Teluk Gilimanuk. OLDI, Vol 35(1); 29 45.

Den Hartog, C. 1970. The seagrass of the world. North-Holand Publ. Co., Amsterdam: 275 pp.

English, S., C. Wilkinson, And V. Baker. 1994. Survey Manual for Tropical Marine Resources. Published on behalf of the ASEAN-Australia Marine Science. Townswile: 241252.

Laksmi, V., A.K. Goel, M.N. Srivastava, D.K. Kulshreshta, R. Raghubir. 2006. Bioactivity of marine organism: part IX - screening of some marine flora from Indian Coasts. IJEB, Vol 44; 137 - 141. 
Lindeboom, H., J. Oijen, Sv. Smith, V. Dupra, T. Yanagi. 2000. Teluk Banten Indonesia Water and Salt Budgets, and Its Implication For The Nutrient Budgets. Diunduh dari http://nest.su.se/mnode/ Asia/Indonesia/telukbanten/tbbu d.htm

Maabuat, P.V., J. Sampekalo, H.E.I. Simbala. 2012. Keanekaragaman lamun di pesisir Pantai Molas, Kecamatan Bunaken, Kota Manado. J. Bios Logos. Vol 2(1): 20 -27 .

Mardesyawati, A. Dan K. Anggraeni. 2009. Persen Penutupan dan Jenis Lamun di kepulauan Seribu. Di dalam Estradivari, Setyawan E, Yusri S, editor. Terumbu Karang Jakarta: Pengamatan Jangka Panjang Terumbu Karang Kepulauan Seribu (2003 - 2007). Jakarta. Yayasan TERANGI.
Pratiwi, R. 2010. Asosiasi Krustasea di ekosistem padang lamun perairan Teluk Lampung. Ilmu Kelautan, Vol 15(2); $66-76$.

Raja-Kannan, R.R., R. Arumugam, S. Meenakhshi, P. Anantharaman. 2010. Thin layer chromatography analysis of antioxidant constituents from seagrasses of Gulf of mannar biosphere reserve, South India. IJCRGG. Vol (2)3; $1526-1530$.

Tomascik, T., A.J. Mah, A. Nontji, M.K. Moosa. 1997. The Ecology of the Indonesian Seas. Part II. Chapter 13 - 23. Periplus Edition (HK) Ltd.

Waycott, M., K. McMahoon, J. Mellors, A. Calladine, D. Kleine. 2004. A Guide Tropical Seagrasses of The Indo-West Pacific. Townsville: James Cook Universitxy. 